\title{
Integrated circuit (IC) timers and pulse generators for laboratory use
}

\author{
ROBERT ADAMSON \\ Florida Atlantic University, Boca Raton, Florida $\$ \$ 4 \$ 2$
}

\begin{abstract}
Two integrated circuits (ICs) suitable for timing and pulse generation, are described together with applicable circuits. The circuit components are inexpensive but highly precise and provide for a wide range of laboratory applications.
\end{abstract}

Two readily available and inexpensive (less than \$4) integrated circuits (ICs) afford precise timing and pulse generation. Each may be used in a monostable (one-shot or timing) mode or as a free-running frequency generator. The ICs are the 555 and the 2240 , available under these designations from most manufacturers, although some (e.g., Lafayette J4-1555 and J4-1214) have idiosyncratically numbered equivalents.

A monostable configuration for generating two successive, but independent, time intervals from two $555 \mathrm{~s}$ is shown in Figure 1. The timing cycle is initiated by a negative ( $\mathrm{V}+$ to ground) pulse to pin 2 of the first 555. This pulse is delivered by closing the switch $\left(\mathrm{S}_{1}\right)$, which provides a brief positive pulse that is inverted by an IC7404 hex inverter (HI) before going to pin 2 . The pulse former-inverter portion of the circuit is not essential for long time intervals $(\geqslant 150 \mathrm{msec})$; in such cases, pin 2 may be shorted directly to ground to initiate the interval.

The output of pin 3 goes from ground to near $\mathrm{V}+$ for the duration of the time interval. The output current is a function of $\mathrm{VH}$, ranging from about $4.5 \mathrm{~mA}$ at $6 \mathrm{~V}$ to almost $8 \mathrm{~mA}$ at $12 \mathrm{~V}$. The lower figure is sufficient to drive a sensitive relay (e.g., Allied R10-E1 series), as shown in Figure 1. The time interval $=1.1 \mathrm{RC}$; however, because of uncertain capacitance values $( \pm 10 \%$ with good ones) and relay lag, the time interval should be empirically determined by driving a stop clock or gated counter. As shown, a diode should be placed across the relay coils to prevent IC damage. To change the time interval, the value of $R_{1}$ may be changed or made variable. A 10-turn precision potentiometer yields reliable settings. Low-leakage tantalum capacitors should be used.

With a 1.5-microfarad tantalum capacitor and a 1 -megohm resistor, the circuit was tested 100 times driving a Struthers-Dunn MRRICDL reed relay (1- to 2 -msec closure time) which, in turn, closed the "Run" contacts on a Lafayette clock/counter (Model 54517). The result was either 1,896 or $1,897 \mathrm{msec}$ on all trials, easily within the relay-clock reliability. Similar results were obtained when a $6,800-0 h m$ resistor was substituted, yielding six readings of $5 \mathrm{msec}$, the remainder being $6 \mathrm{msec}$.
At the conclusion of the time interval, pin 3 of $555_{1}$ goes negative. This delivers a brief negative pulse through the RC pulse former to the second 555, which initiates the second time interval. Not shown, but possible, is the sequencing of several timers, with independent time intervals and controlling separate events.

The second timer may be reset by grounding pin 4 of $555_{2}$ through the pushbutton switch $\left(\mathrm{SW}_{2}\right)$. The output of the second timer could start a tachistoscopic presentation and simultaneously start a clock. The subject's response through the pushbutton $\left(\mathrm{SW}_{2}\right)$, shown in Figure $1\left(555_{2}\right)$, would stop the display and the clock, thus providing a response time measure.

A free-running or astable configuration for the 555 is shown in Figure 2. The period of oscillation is determined by the time required to charge the timing capacity $(\mathrm{C})$ to a trigger condition (a function of both $\mathrm{RA}$ and RB) and the discharge time (a function of RB only). When RA is kept relatively small with reference to $\mathrm{RB}$, the output closely approximates a square wave, with a time interval from less than $1 \mathrm{msec}$ to over $10 \mathrm{~min}$.

The use of a 2240 IC affords a considerably extended timing capability. Figure 3 shows a suggested wiring diagram. The time interval is initiated by closing $\mathbf{S W}_{\mathbf{1}}$. This initiates a momentary pulse to pin 11 . The duration of the base time interval $(t)$ is determined by values of $\mathrm{R}$ and $\mathrm{C}$. For reasons that will be apparent, $t$ should be $\mathrm{a}$ fairly short interval (e.g., $5 \mathrm{msec}$ ); hence, the values

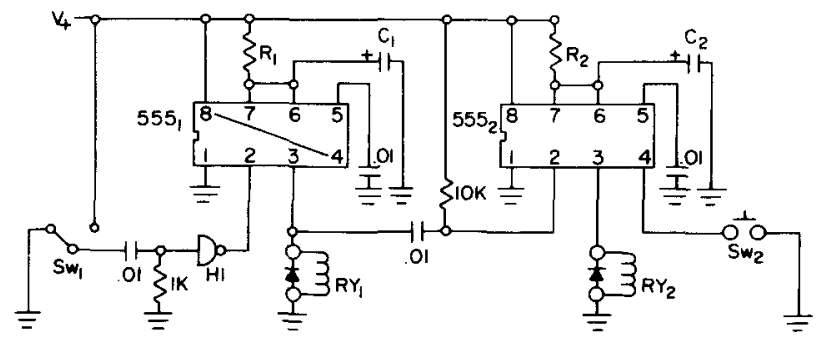

Figure 1. A 555 timer configuration providing for two successive time intervals with independent event control and reset capability. Pins 4 and 8 of 555 are connected. Pins 4 and 8 of $555_{2}$ are not connected when $\mathrm{SW}_{2}$ is used. 


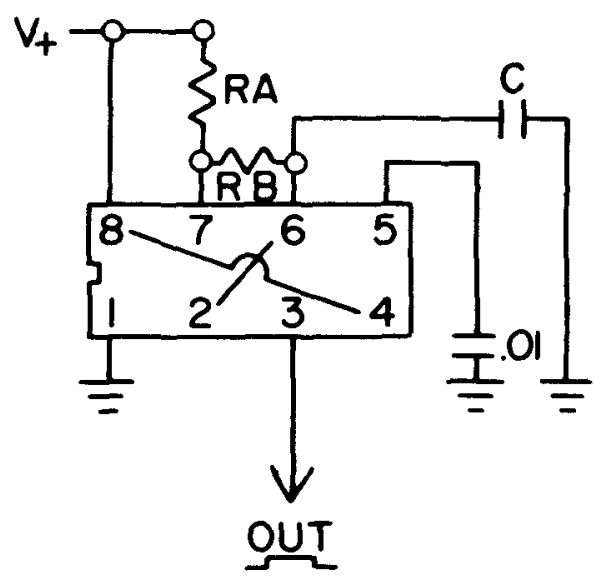

Figure 2. The 555 astable (pulse-generator) mode, in which pulse length and frequency is a function of (RA + RB) $C$.

of $R$ and $C$ could be approximately 5 kohms and 1.0 microfarad or any other such multiple.

The major advantage of the 2240 is that it affords programmable increments of $t$ (up to $225 \mathrm{t}$ ). This is accomplished by the binary counter output pins 1.8 to a common output bus. Pin 1 alone yields an output equal to $t$; pin 2, $2 \mathrm{t}$; pin $3,4 \mathrm{t}$; pin $4,8 \mathrm{t}$; etc. The time intervals associated with each pin may be summed by switching them in parallel to the output bus. Thus, for example, closing $\mathrm{SW}_{3}(4 \mathrm{t})$ and $\mathrm{SW}_{5}(16 \mathrm{t})$ yields an interval of $20 \mathrm{t}$. If $\mathrm{t}$ is $5 \mathrm{msec}$, the range of durations available is from 5 to $1,275 \mathrm{msec}$ in 5 -msec steps. As Figure 3 indicates, when the 2240 is triggered, its output goes low (V+to ground) for the duration of the interval. By feeding the output through HI or shorted inputs to an IC 7400 NAND gate, the output is converted to a positive going pulse. With $\mathrm{V}+$ from 5 to $12 \mathrm{~V}$, the pulse varies between approximately 4 and $10 \mathrm{~mA}$, which is sufficient to drive a sensitive relay for external control purposes.

When $\mathrm{SW}_{2}$ is closed, the IC operates as a monostable timer. It may also be used in a free-running mode as a square-wave pulse generator by simply opening $\mathrm{SW}_{2}$. The trigger pulse to pin 11 initiates counting, which continues until a $\mathrm{V}+$ signal is applied to pin 10 . In the astable mode, both the 555 and 2240 circuits can supplant more expensive and cumbersome crystaldivider circuits employed as time bases. Thus, if $t$ is $1 \mathrm{msec}$, the output can serve as a stop-clock time base. Such a circuit, for a $555 \quad(\mathrm{RA}=300, \mathrm{RB}=684$, $\mathrm{C}=.1$ microfarad, $\mathrm{V}+=5$ ), has been tested through a $1-\sec$ gate (Monsanto counter-timer, Model 03A) over 10 -min gating at $1000 \pm 1 \mathrm{msec}$, comparable to crystal reliability. The output may feed directly into the count input of a decoder-display driver panel (such as a Durgin $\&$ Brown DPD-104, at about $\$ 45$ ) for permanent incorporation as a stop clock.

There are several more detailed descriptions of both ICs. One of the most comprehensive is in the Calectro Semiconductor Data and Applications Handbook, available at Lafayette Radio stores.

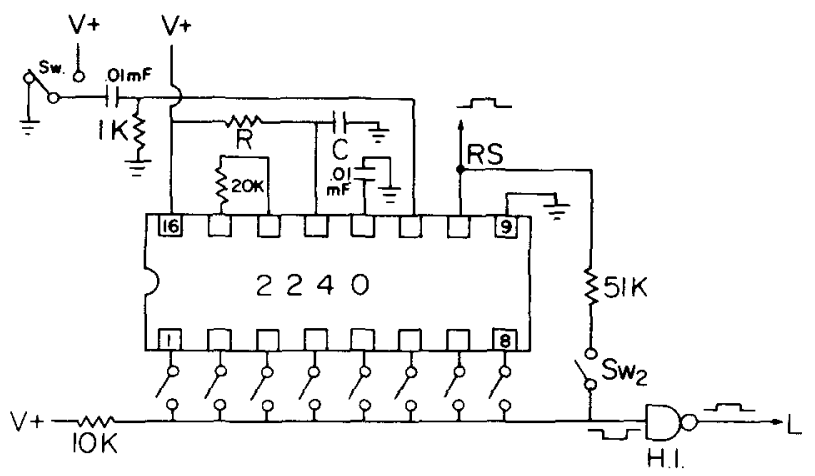

Figure 3. The 2240 configuration for both timing and pulse generation with binary increments to an RC time base.

(Received for publication December 3, 1976; revision accepted January $25,1977$. 